RUNNING HEAD: AUTOBIOGRAPHICAL MEMORY AND MOTHER-CHILD

\title{
RELATIONSHIPS
}

The Specificity of Autobiographical Memories in Early Adolescence:

The Role of Mother-Child Communication and Attachment-related Beliefs

Guy Bosmans ${ }^{1}$

Adinda Dujardin ${ }^{1}$

Filip Raes ${ }^{2}$

Caroline Braet ${ }^{3}$

${ }^{1}$ Parenting and Special Education Research group, University of Leuven

${ }^{2}$ Department of Psychology, University of Leuven

${ }^{3}$ Department of Developmental, Personality, and Social Psychology, Ghent University 


\begin{abstract}
Although autobiographical memory specificity is an important developmental feature fostering adaptation throughout life, little is known about factors related to inter-individual differences in autobiographical memory specificity. The current study investigated associations with early adolescents' communication with mother about their experiences and their trust in her support. For this reason, 80 general population children (ages ranging from 10-13) were asked to retrieve specific memories of interactions with mother. Communication and trust in maternal support were measured using questionnaires. Results showed that specificity of autobiographical memories was directly linked with communication, but not witch trust in maternal support. Moreover, evidence was found in favor of an indirect effect of trust on autobiographical memory specificity through communication. This study suggests that trust-related mother-child communication is important to understand interindividual differences in autobiographical memory specificity.
\end{abstract}




\section{The Specificity of Autobiographical Memories in Early Adolescence:}

\section{The Role of Mother-Child Communication and Attachment-related Beliefs}

Specific autobiographical memories are very concrete recollections of events that occurred at a specific moment in one's personal past (Williams, et al., 2007). Impaired retrieval of specific autobiographical recollections translates into overgeneral memories (e.g., when asked for a memory with regard to the feeling "shame", an overgeneral answer might be: "every time my teacher punished me in front of the classroom”). Overgeneral memories play a crucial role in the development of depression, PTSD, impaired problem solving, and unhealthy repetitive thinking (Williams et al., 2007). To date, little is known about the mechanisms explaining differences in autobiographical memory specificity (Valentino, 2011). Nevertheless, identifying factors related to decreased specificity might be essential to better understand maladaptive development. To increase our understanding of these factors, the current study builds on Kuyken, Howell, and Dalgleish's (2006) suggestion that adverse mother-child relationships might be essential to understand decreased autobiographical memory specificity.

Mother-child relationships provide a unique context in which children develop autobiographical memories (e.g., Fivush, 2006; Newcombe \& Reese, 2004), shaping different autobiographical memory features, such as the level of elaboration, the coherence (e.g., Fivush, 1994; Fivush, Haden, \& Reese, 2006), and the emotional content of recollections (Bird \& Reese, 2006). Consequently, it is reasonable to assume that overgeneral memories could be the result of maladaptive mother-child relations. Although links between mother-child relations and autobiographical memory specificity have not yet been investigated, three hypotheses have been put forward suggesting such an association (Fivush, 2006; Valentino, 2011): (1) lack of mother-child communication about children's experiences might decrease children's ability to recall specific events; (2) insecure attachment-related beliefs might directly decrease autobiographical memory specificity as the result of suppression of specific recollections to avoid emotions experienced during interactions with rejecting mothers (defensive exclusion hypothesis); (3) insecure attachment-related beliefs might decrease mother-child 
communication about children's experiences, which in turn might decrease the ability to recall specific events. As already in early adolescence meaningful differences in autobiographical memory specificity were found (Drummond, Dritschel, Astell, O’Carroll, \& Dalgleish, 2006; Raes, Verstraeten, Bijttebier, Vasey, \& Dalgleish, 2010; Vrielynck, Deplus, \& Philippot, 2007), and as previous research found that, in early adolescence, similar cognitive vulnerabilities are developed during interactions with attachment figures (Mezulis, Hyde, \& Abramson, 2006), the current study investigated these three hypotheses in that age-group.

\section{Mother-child Communication and Autobiographical Memory Specificity}

A first hypothesis considers communication between children and mothers about children's experiences as an important determinant of the quality of autobiographical memories, including specificity of recollections. Previous research in early childhood found that quality of mother-child conversation predicts young children's ability to recall past events. Mothers who discuss past events in an emotionally rich and detailed way have children with more detailed autobiographical memories

(e.g., Harley \& Reese, 1999; Laible \& Song, 2006; Reese \& Newcombe, 2007). It has been argued that discussing causes and consequences of emotions is crucial to help young children understand the meaning of experiences before these experiences can be integrated into autobiographical memories (Bird \& Reese, 2006). In the same vein, Valentino (2011) argued that mother-child communication might also increase children's ability to retrieve specific autobiographical memories.

Less research has focused on the association between mother-child communication and the ability to retrieve autobiographical memories beyond early childhood. Nevertheless, even in early adolescence, mother-child communication continues to be important for children's emotional understanding (Shipman and Zeman (1999) and as an increasingly important affect-regulating strategy (Mayseless, 2005). These studies suggest that it remains important to investigate outcomes of motherchild communication about children's experiences in early adolescence. Therefore, the current study's first aim was to test whether children who communicate less with mother about their experiences have less specific recollections. 


\section{Attachment-related Beliefs and Autobiographical Memory Specificity}

A second hypothesis considers lack of autobiographical memory specificity as a cognitive information processing deficit related to insecure attachment expectations (Dykas \& Cassidy, 2011; Valentino, 2011). These expectations are determined by children's experiences with caregivers' support or lack of support during distress. Bowlby (1980) and Main (1990) hypothesized that individuals develop an unconscious defensive exclusion strategy if they are frequently exposed to the distress related to experiencing rejection, and absence of care and support. Consequently, insecurely attached individuals are expected to report less specific autobiographical memories to avoid negative emotions that could be activated by recalling insecure attachment-related information. This defensive exclusion hypothesis is very similar to Williams's (1996) functional avoidance theory which suggests that overgeneral recollections protect individuals from reactivating intense painful negative affect related to specific recollections (also see: Raes, Hermans, de Decker, Eelen, \& Williams, 2003; Raes, Hermans, Williams, \& Eelen, 2006; Williams et al., 2007). Ainsworth (e.g., 1973; 1992) argued that secure attachment reflects in its definition children's certainty or trust in caregivers' availability, responsiveness, and ability to provide assistance, safety, and comfort, while insecure attachment reflects children's uncertainty or lack of trust. Therefore, the current study's second aim was to investigate whether less trust in maternal support is related to overall less specific recollections.

\section{Attachment-related Beliefs, Communication, and Autobiographical Memory Specificity}

A final hypothesis builds on the finding that adequate mother-child communication develops as a function of secure attachment relationships (Newcombe \& Reese, 2004). This finding led Fivush (2006) to propose a theoretical model in which securely attached mother-child dyads engage in more elaborated reminiscing, allowing children to develop more coherent explicit representations of attachment-related events. Fivush's (2006) hypothesis might be relevant to understand inter-individual differences in specificity of autobiographical memories as well. This hypothesis differs from the current study's second hypothesis, where links between insecure attachment and decreased specificity of autobiographical memories are expected to reflect a direct deficit in the cognitive processing of 
attachment-related information. Instead, the third hypothesis suggests that attachment-related beliefs will determine whether or not children will communicate with mother about their experiences, thus indirectly increasing the ability to retrieve specific autobiographical memories. To test this hypothesis, the current study's third aim was to test whether children's trust in maternal support is indirectly related to specificity of autobiographical memories through communication (see Figure 1).

\section{The Current Study}

In order to test the current study's hypotheses, both trust in maternal support and mother-child communication were measured using self-report instruments. In early adolescence, self-report is currently not only the most widely used approach to measure attachment-related differences, but it is also the approach for which most validity support has been found (Kerns, 2008). Moreover, attachment security is a broad and rich construct in which affective, cognitive and behavioral components have each been considered central. Although theoretically and descriptively important, this richness has made it sometimes difficult to study mechanisms guided by attachment status. Therefore, the present study will focus on children's explicit expectations regarding mother's availability and responsiveness. This will allow to investigate mechanisms concerning one specific cognitive component of the broader attachment construct.

While our hypotheses would suggest that associations between memory specificity and communication should be found independently of the content of the recalled events, evidence in favor of defensive exclusion should be most pronounced when children recall events related to mother-child interactions. Therefore, the original Autobiographical Memory Test (AMT, Williams and Broadbent, 1986) was adapted. Children were asked to recall specific events related to positive and negative feelings they experienced when being together with mother. Importantly, Williams et al. (2007) point out that overgeneral memory as an avoidance strategy can only be successful if it is applied not just with respect to negative memories but to memory in general. This was confirmed by a meta-analysis by van Vreeswijk and De Wilde (2004) which showed that reduced specificity occurs independently of the valence of emotions and by Griffith and colleagues (2009) who demonstrated that the AMT 
measures one general factor and not two independent valence-related factors. Therefore, the current study's responses to the positive and negative AMT items were summarized in one AMT specificity score.

In summary, the current study aimed to increase our understanding of decreased autobiographical memory specificity in early adolescence. Three hypotheses were tested: (1) whether less self-reported trust in maternal support is related to less specific autobiographical memories regarding interactions with mother; (2) whether children who report to communicate less with mother about their experiences have less specific autobiographical memories; and (3) whether trust is indirectly linked with specificity of autobiographical memories through children's reported communication with mother. As depression affects memory processes (Timbremont \& Braet, 2004) and is related to decreased specificity of autobiographical memories (Williams et al., 2007), the studied associations were controlled for possible effects of children's depressive symptoms.

\section{Method}

\section{Participants}

Eighty elementary school children ( 22 boys, 58 girls) participated to the study with ages ranging from $10-13(M=11, S D=.69), 25 \%$ of which had divorced parents. All children had been primarily raised by their mother during the first three years of their life and reported on the relationship with their biological mother. Regarding parental level of education, $1 \%$ of the mothers had an elementary school degree, $32.7 \%$ had a high school degree, $35.7 \%$ had a post-high school technical training or a technical bachelor degree, and $11.2 \%$ had a university master degree. Furthermore, $32.6 \%$ of the fathers had a high school degree, $28.6 \%$ had a post-high school technical training or a technical bachelor degree, and $18.4 \%$ had a university master degree.

\section{Procedure}


Using a letter distributed in the classrooms of the fourth, fifth, and sixth grade of elementary schools, we invited volunteering children and their parents to a study on the relationship between children and their mother. The letter informed the parents about the content of the study and asked their approval to participate. Approximately $40 \%$ of the parents who received a letter gave their informed consent. The participating families were visited by a trained bachelor psychology student. All invited children chose to participate after being personally informed about the content and the methodology of the study and about their right to refuse participation.

At the beginning of the experiment every child was individually interviewed about their mother by a trainee in clinical psychology. During the interview, children were asked to describe their relationship with mother, and to recall how they coped with events during which they were distressed, in pain, ill, or overwhelmed by separation or loss of a dear one. Following the theoretical assumptions of attachment interviews, talking with children about their mother should activate the attachment system (e.g., Target, Fonagy, \& Shmueli-Goetz, 2003). Comparable strategies have already been used to activate the attachment system in previous attachment research on this age group (e.g., Bosmans, Braet, Koster, \& De Raedt, 2009), and in adult attachment research (e.g., Dewitte, Koster, De Houwer, \& Buysse, 2007). Then the Autobiographical Memory Test (AMT) was administered. As this study was part of a larger study, other tasks were administered as well. Afterwards, children filled out the questionnaires. The local ethics committee approved the study design.

\section{Measures}

Autobiographical Memory Test (AMT; Williams \& Broadbent, 1986). To test AM specificity the written version of the AMT was used (see Raes et al., 2010). Ten different cue words were presented ( 5 positive cues like safe or proud and 5 negative cues like afraid and ashamed). For the purpose of this study, the original AMT was adapted. Children were asked to write down for cue words a specific memory about an occasion during which they were together with mother (i.e., a memory referring to one particular occasion or event that happened on a particular day and did not last longer than a day A written AMT has been used successfully before in this age group replicating adult 
research, which suggests that this approach is useful in this age-group (Raes et al., 2010). Before the test, children read together with the experimenter an example cue word (recall a time when you felt "good" while being with your mom) and then different possible responses reflecting different levels of specificity amongst which a clear illustration of a specific answer.

Each response was coded as either a specific memory (e.g., ashamed: "when the eggs broke in the pocket of my jacket and mom had to wash it"), a general memory (e.g., safe: "when I am with my mom during a thunderstorm"), a no memory (children answering: "I can't remember"), or a no response (when nothing was written). Inter-rater agreement was high $(\kappa=.89)$. Responses to the positive and negative AMT items were summarized in one AMT specificity score.

As the data were collected in two cross-sectional waves for organizational reasons, one cue word was changed in the second wave (pleasant instead of relaxed). However, changing the cue had no effect on the overall AMT-Specificity score, $F(1,78)=.05, n s$. Therefore, we combined the two samples in one large sample.

People In My Life Questionnaire. Trust in maternal support and inclination to communicate about negative affect were estimated with the Trust- and Communication-subscales of the People In My Life Questionnaire which is designed to measure 10 to 12-year-old children's representations of attachment figures (PIML, Ridenour, Greenberg, \& Cook, 2006). This questionnaire is a child-friendly version of the Inventory of Parent and Peer Attachment (Armsden \& Greenberg, 1987), which investigates Trust in the attachment figures' support, Communication about negative affect, and Alienation from the attachment figure (e.g., Allen, Porter, MacFarland, et al., 2007; Belsky, Jaffee, Hsieh, \& Silva, 2001). This measure has been widely used and has good psychometrics (Allen, in press). Its validity is suggested for example by links with attachment figure utilization, self-esteem, and parenting quality (e.g., Armsden \& Greenberg, 1987; Gullone \& Robinson, 2005).

For the current study, only the items of the Trust- and Communication-scales focusing on the relationship with mother were used. Trust is conceptualized as the positive affective/cognitive experiences of trust in the accessibility and responsiveness of attachment figures ( 10 items, e.g. "I can 
count on my mother to help me when I have a problem"). The Communication scale consists of 5 items (e.g., "I talk to my parents when I am having a problem.”). Children responded on a 4-point Likert-scale ranging from 1 (almost never true) to 4 (almost always true). The Trust scale was previously linked with maternal parenting behaviors and the attentional processing of mother (e.g., Bosmans et al., 2009). The Communication-scale moderated the effect of children's exposure to Hurricane Katrina on the development of anxiety and trauma symptoms (e.g., Costa, Weems, \& Pina, 2009). In the current sample we found the Trust scale $(\alpha=.65)$ and the Communication scale $(\alpha=.70)$ to have adequate reliability.

Child Depression Inventory (CDI; Kovacs, 1992; Timbremont \& Braet, 2002). The children and adolescents completed a Dutch version of the CDI to assess current mood. The CDI is used for children and adolescents aged 7 to 17. It includes 27 items measuring cognitive, affective and behavioral symptoms of depression in children. Each item consists of three statements graded in order of increasing severity from 0 to 2 and children select the item that characterized them best during the past two weeks. The item scores are combined into a total Depressive Symptoms score. The original questionnaire has relatively high levels of internal consistency, test-retest reliability and predictive, convergent and construct validity, especially in non-clinical populations (Craighead, Smucker, Craighead, \& Ilardi, 1998). Psychometric results for the Dutch version are promising. The internal consistency of the Dutch CDI is 0.80 , the one-month test-retest reliability is 0.81 (Timbremont \& Braet, 2002). In the current sample, $\alpha=.82$.

\section{Results}

\section{Preliminary Analyses}

No data were missing. Children recalled on average 9.6 events (specific and general memories combined) for 10 cue words. Number of recalled events was not correlated with Trust $(r=.04, n s)$, or with Communication $(r=.07, n s)$, but with Depressive Symptoms $(r=-.52, p<.001)$. In total, $69 \%$ of the recalled events were coded as specific memories ${ }^{1}$. On average, children were able to provide six specific memories to the ten cue words. Although a substantial number of children had divorced 
parents (25\%), and although divorce could have had a negative impact on the frequency of motherchild interactions and number of occasions to recall, having divorced parents was not related to AMTSpecificity $(F(1,78)=.228, n s)$. ANOVA analyses showed that gender had an effect on level of Trust, $F(1,78)=8.27, p<.01\left(M_{\text {girls }}=36.24, S D_{\text {girls }}=3.07 ; M_{\text {boys }}=33.68, S D_{\text {boys }}=4.61\right)$, and a marginally significant effect on AMT-Specificity, $F(1,78)=3.58, p=.06\left(M_{\text {girls }}=6.22, S D_{\text {girls }}=2.13\right.$; $M_{\text {boys }}=7.23, S D_{\text {boys }}=2.09$ ), but not on Depressive Symptoms and Communication. Age was significantly correlated with Trust $(r=.22, p<.05)$, marginally significantly with Depressive Symptoms $(r=.20 ; p=.07)$, but not with AMT-Specificity and Communication. In our random sample, $17 \%$ had a CDI score above the cut-off of 16 (Timbremont, Braet, \& Dreesen, 2004). Table 1 shows that children with higher scores on Depressive Symptoms retrieved less specific autobiographical memories.

\section{Communication and Autobiographical Memory Specificity}

Table 1 shows the correlations between the main variables of the current study. In line with the current study's first hypothesis, Communication was significantly correlated with AMT-Specificity. To test whether this effect was specific for Communication and not explained by children's depressed mood, a Multiple Regression Analysis was conducted with Age, Gender, and Depression as control variables and Communication as predictor of AMT-Specificity. Table 2 shows that the relationship between Communication and AMT-specificity remains significant after controlling for Depression. Moreover, the effect of Depression on AMT-Specificity disappears when Communication is taken into account. This model explains $15 \%$ of the variance in AMT-Specificity.

\section{Trust and Autobiographical Memory Specificity}

Contrary to the current study's second hypothesis, Trust was not correlated with AMTSpecificity. 
Although not correlated with AMT-Specificity, Trust is correlated with Communication and Communication is correlated with AMT-Specificity (Table 1). Therefore, we tested whether Trust is indirectly linked with AMT-Specificity through Communication. Following the recommendations of McKinnon, Lockwood, and Williams (2004) we used a nonparametric resampling method (biascorrected bootstrap; Preacher \& Hayes, 2008) with 5,000 resamples drawn with replacement from the original sample $(\mathrm{n}=80)$ to derive the trust interval $(\mathrm{CI})$ for the indirect effect. To that end, we used the SPSS Macro provided by Preacher and Hayes (2004). After controlling for the effect of Depression, the true total indirect effect of Trust, expressed in unstandardized regression weights, was estimated to lie between .02 and $.28(S E=.05)$ with $99 \%$ CI. Because zero is not in the $99 \%$ CI, we can conclude that the indirect effect of Trust is significantly different from zero at $p<.01$ (two tailed). The entire model explains $17 \%$ of the variance in AMT-Specificity. Surprisingly, adding the indirect effect to the model led to a significant direct negative effect of Trust (unstandardized $b=-.18, p<.05$ ).

\section{Discussion}

The current study investigated links between characteristics of the mother-child relationship and inter-individual differences in autobiographical memory specificity. For this purpose, it was tested in early adolescents whether attachment-related autobiographical memory specificity is (1) related to self-reported mother-child communication; (2) directly related to self-reported trust in maternal support; or (3) whether trust in maternal support is indirectly related to specificity through children's perceived communication with mother about their experiences. Results support the current study's first hypothesis, showing that more child-reported communication is related to more specific autobiographical memories. Moreover, the data support the current study's hypothesis that more trust in maternal support is related to more self-reported communication about their experiences with mother and through this indirect link to enhanced retrieval of specific autobiographical memories. The implications of these findings for our understanding of autobiographical memory specificity and for future research will be discussed in the following paragraphs.

\section{Communication and Autobiographical Memory Specificity}


The current results suggest that children's perceived communication with mother is related to autobiographical memory specificity. This supports Valentino's (2011) hypothesis that the mechanism explaining links between mother-child conversation in early childhood and other features of autobiographical memories, might explain autobiographical memory specificity (Valentino, 2011). In early childhood, this mechanism was identified as follows. Through conversation, mothers help their child to reexamine, reinstate, and bring together their memory for personal experiences in everyday conversation about past experiences (e.g., Harley \& Reese, 1999; Hudson, 1993; Steele, Steele, Croft, \& Fonagy, 1999; Reese \& Newcombe, 2007). As a result, young children learn to understand eventrelated emotions which fosters autobiographical memory development (Wang, 2008). Further corroborating the importance of early childhood mother-child conversations to understand autobiographical memory development, a direct link was previously found between early childhood mother-child conversations and quality of adolescent autobiographical recollections (Reese, Jack, \& White, 2010).

The current study provides two important additions to the existing literature on mother-child reminiscing. Firstly, the current study provides first evidence suggesting that understanding the development of the specificity of autobiographical memories requires focusing on the quality of mother-child communication. Secondly, the current cross-sectional correlations suggest that motherchild communication might be related to the quality of autobiographical memories beyond early childhood. It remains to be seen whether the current study's link between communication and early adolescent autobiographical memory specificity results from a continuation of an established early childhood mother-child conversation pattern, reflecting a similar direct effect as found by Reese and colleagues (2010), or whether mother-child communication during later childhood has an independent effect on autobiographical memory development. Future research should now investigate whether the effects replicate when communication is coded from observational data as is most often done in mother-child reminiscing literature. 


\section{Trust and Autobiographical Memory Specificity}

Specificity of autobiographical memories was not related to self-reported trust in maternal support. This seems to suggest that the role of attachment in explaining reduced memory specificity is not that of a direct, merely cognitive, schema-driven information processing deficit. Although these results inform the defensive exclusion hypothesis, three considerations can be made regarding these results suggesting that the current results cannot be considered a final test of this hypothesis.

Firstly, it could be argued that evidence for the defensive exclusion hypothesis should mainly be found when recalling adverse interactions with mother. According to Bowlby's (1980) hypothesis, insecurely attached children avoid negative emotions that could be activated by recalling insecure interactions with mother. However, reanalyzing the data for negative recollections alone still did not reveal a significant association between AMT-specificity for negative recollections and Trust $(r=-.07$, $n s)$.

Secondly, the current study cannot rule out links with other components of the attachment construct. Self-reports to measure attachment-related beliefs are often criticized for over-identifying security (Ainsworth, 1985). Consequently, the lack of support for the defensive exclusion hypothesis might result from measurement error. Future research might benefit from measuring less explicit and more automatic components of the attachment system. One interesting recently developed assessment tool could be Waters and Waters' (2006) Secure Base Script test. Although the early adolescent version is still under construction (Waters et al., 2011), this approach could prove crucial to further elaborate our understanding of attachment-related autobiographical memory specificity. Also, Edelstein (2006) demonstrated that avoidant memory impairments are specifically relevant for individuals scoring high on avoidant attachment. Therefore, it could be important to separate out different types of insecure attachment like anxious and avoidant attachment. By the time the current data were collected, no convincing tool was available to measure avoidant attachment (Dwyer, 2005). 
The questionnaire used by Edelstein (2006) is recently adjusted to early adolescence (Brenning, Soenens, Braet, \& Bosmans, in press) and can be administered in future research.

Finally, given the importance of experienced support in attachment relationships, instructing participants to recall events characterized by (absence of) experienced support could have yielded stronger effects. Yet, such an instruction would fundamentally change the AMT, making it difficult to integrate the current results into the existing autobiographical memory specificity literature.

In spite of these limitations, it is important to conclude that the current study provided a first test of the defensive exclusion hypothesis, but found no support for this hypothesis. Therefore, the current null finding is important as it puts into question a widely accepted assumption of attachment theory.

\section{Trust Linked with Autobiographical Memory Specificity through Communication}

Finally, although no direct link was found between trust in maternal support and the specificity of autobiographical memories concerning mother, trust was indirectly linked with specificity of these autobiographical memories through perceived communication. Our results suggest that children who trust less in maternal support, report to communicate more with their mother about negative affect, and have, in turn, more specific memories concerning interactions with mother. This finding expands previous research that showed that the quality of the attachment relationship affects the quality of mother-child conversation (Newcombe \& Reese, 2004). This supports Fivush' (2006) hypothesis that the quality of attachment relationships is important for the development of autobiographical memories as conversations that promote autobiographical memory development mainly occur in secure relationships.

Surprisingly, data suggests that taking into account this indirect effect reveals a significant negative association between Trust and AMT-Specificity. Due to the high positive correlation between Trust and Communication, controlling for communication takes out a substantial amount of variance in Trust that is related to positive outcomes. The remaining variance in trust represents a more negative component which appears to become significantly linked with AMT-Specificity. Although 
we conjecture that this effect is the result of statistical coincidence, future research is needed to rule out the possibility that, in addition to current theory, children with less Trust have very specific recollections of interactions with mother after controlling for the role of quality of Communication.

This study found marginally significant effects of gender on memory specificity and significant effects on trust in maternal support. Similar gender differences in attachment are increasingly found from middle childhood onwards (e.g., Sarracino, Presaghi, Degni, Innamorati, 2011). Similar findings made Del Guidice and Belsky (2010) argue that emerging gender differences in attachment are evolutionary important, reflecting the development of reproduction systems.

Although all variables were measured using the same informant, the use of multiple methods (self-report measures and a performance task) reduces the likelihood that the associations only reflect a reporter bias. Also importantly, these associations could have been the result of children's underlying negative affective state. Nevertheless, the associations remained significant after controlling for depressive symptoms. Moreover, in these analyses, the initial effect of depression was no longer significant, suggesting that attachment-related autobiographical memory specificity might be uniquely related to communication in this age-group.

\section{Limitations}

In the current study, attachment-related autobiographical memory specificity was measured using a written version of the AMT. Future research in children should test whether the present results replicate using an orally administered AMT. For example, children might perform differently/better on the AMT when interviewed, as it could be a more appropriate strategy to prompt specific memories in this age-group. However, the current version did elicit a high number of specific recollections and amount of specific recollections was not related to age or cognitive maturity. Also, the current results replicate earlier work with a written version (Raes et al., 2010) and an oral version of the AMT (Vrielynck et al., 2007). In these previous studies, specificity of autobiographical memories was related to early adolescent depression, independent of the type of the task. This suggests that early adolescent memory specificity can be meaningfully measured with the written version of the AMT. 
Also, the test started with an interview to activate the attachment system, a procedure often used in attachment studies (Dewitte et al., 2007). The procedure's main goal is to make sure that children's schemas regarding mother are activated at the beginning of the experiment (e.g., Dewitte et al., 2007). Nevertheless, this approach might also have primed children's memories, inflating the correlations between the current study's variables. Although the insignificant correlation between trust and AMT-Specificity suggests that the activation procedure might not have compromised the results, it remains important to test in future research whether the activation procedure is necessary to obtain the same results.

Finally, the cross-sectional nature of the current data and the correlational analyses do not allow deducting causal pathways (Kraemer, Stice, Kazdin, Offord, \& Kupfer, 2001). Nevertheless, these findings are the first to confirm Valentino's (2011) hypothesis that studying the mother-child relationship has potentially great value for furthering our understanding of the development of autobiographical memory specificity.

\section{Future Directions}

The current study suggests that mother-child communication about children's experiences is related to autobiographical memory specificity. Results indicate that children who trust more in maternal support, report to communicate more with their mother about their experiences, and have, in turn, more specific memories concerning mother. As reduced specificity of autobiographical memories appears to be a stable construct that endures when depression is in remission (e.g., Mackinger, Pachinger, Leibetseder, \& Fartracek, 2000) and predicts the course of depression (e.g., Raes et al., 2006), these findings might inform future developmental psychopathology research. A first next step would be to investigate whether communication plays a role in the development of depression through autobiographical memory specificity or vice versa. Also, a crucial question to investigate is whether quality of the mother-child relationship mediates the often reported association between traumatic experiences (see Williams et al., 2007) and specificity of autobiographical memories. 
The current findings might be relevant for clinical practice as well. One successful approach in adults to reduce this cognitive vulnerability is to provide memory specificity training (Raes, Williams, $\&$ Hermans, 2009). However, in line with the frequently documented importance of mother-child relationships in (early) adolescent depression (e.g., Bosmans, Braet, Beyers, Van Leeuwen, \& Van Vlierberghe, 2011; Brumariu \& Kerns, 2010), the current results suggest that improving the quality of mother-child communication might be an adequate intervention strategy in younger age-groups. One promising new approach is Attachment Based Family Therapy for depressed adolescents (ABFT, Diamond, Reiss, Diamond, Siqueland, \& Isaacs, 2002). ABFT aims at increasing the quality of parentadolescent communication about the adolescents' negative affective experiences and has been empirically evaluated as an effective intervention for adolescent depression (Weisz, McCarthy, \& Valeri, 2006). As our study shows that parent-child communication remains important during early adolescence, ABFT might have a positive influence on the specificity of autobiographical memories and might therefore prevent children to relapse. 


\section{References}

Ainsworth, M. D. S. (1973). The development of infant-mother attachment. In B.M. Caldwell \& H. N. Ricciuti (Eds.), Review of child development research (pp. 1-94). Chicago: University of Chicago Press.

Ainsworth, M.D.S. (1985), Attachments across the life span. Bulletin of the New York Academy of Medicine, 61, 792-812.

Ainsworth, M.D.S (1991). On security. Retrieved (April 19, 2012) from http://www.psychology.sunysb.edu/attachment/pdf/mda_security.pdf

Allen, J.P. (in press). Assessing attachment in adolescence. In E. Waters, B. Vaughn, \& H. Waters (Eds). Measuring Attachment. New York; Guilford.

Allen, J. P., Porter, M. R., McFarland, F. C., McElhaney, K. B., and Marsh, P. A. (2007). The relation of attachment security to adolescents' parental and peer relationships, depression, and externalizing behavior. Child Development, 1222-1239.

Armsden, G. C., \& Greenberg, M. T., (1987). The Inventory of Parent and Peer Attachment: Individual differences and their relationship to psychological well-being in adolescence. Journal of Youth and Adolescence, 16, 427-454.

Belsky, J., Jaffee, S., Hsieh, K., and Silva, P. (2001). Childrearing antecedents of intergenerational relations in young adulthood: A prospective study. Developmental Psychology, 801-814.

Bird, A. \& Reese, E. (2006). Emotional reminiscing and the development of an autobiographical self. Developmental Psychology, 42, 613-626. 
Bosmans, G., Braet, C., Koster, E., \& De Raedt, R. (2009). Attachment security is linked with attentional breadth in middle childhood. Journal of Clinical Child and Adolescent Psychology, $38,872-882$.

Bosmans, G., Braet, C., Beyers, W., Van Vlierberghe, L., Van Leeuwen, K. (2011). Power assertive discipline and internalizing problems in adolescents: The role of attachment. Parenting: Science and Practice, 11, 34-55.

Bowlby, J. (1980). Attachment and loss: Vol. 3. Loss, sadness, and depression. New York: Basic.

Brenning, K., Soenens, B., Braet, C., \& Bosmans, G. (in press). Attachment and depressive symptoms in middle childhood and pre-adolescence: Testing the applicability of the emotion regulation model of attachment. Journal of Personal Relationships.

Brumariu, L. E., \& Kerns, K. A. (2010). Parent-child attachment and internalizing symptoms in childhood and adolescence: A review of empirical findings and future directions. Development and psychopathology, 22(1), 177-203.

Costa, N. M., Weems, C. F., \& Pina, A. A. (2009). Hurricane Katrina and youth anxiety: The role of perceived attachment beliefs and parenting behaviors. Journal of Anxiety Disorders, 23, 935941.

Craighead, W. E., Smucker, M. R., Craighead, L. W., \& Ilardi, S. S. (1998). Factor analysis of the Children's Depression Inventory in a community sample. Psychological Assessment, 10, 156165.

Del Giudice, M., \& Belsky, J. (2010). Sex differences in attachment emerge in middle childhood: An evolutionary hypothesis. Child Development Perspectives, 4, 97-105.

Dewitte, M., Koster, E. H. W., De Houwer, J., \& Buysse, A. (2007). Attentive processing of threat and adult attachment: A dot-probe study. Behaviour Research and Therapy, 45, 1307-1317.

Diamond, G. S., Reiss, B., Diamond, G. M., Siqueland, L., \& Isaacs, L. (2002). Attachment-based family therapy for depressed adolescents: A treatment development study. Journal of the American Academy of Child and Adolescent Psychiatry, 41, 1190-1196. 
Drummond, L. E., Dritschel, B., Astell, A., O’Carroll, R. E., \& Dalgleish, T. (2006). Effects of age, dysphoria, and emotion-focusing on autobiographical memory specificity in children. Cognition and Emotion, 20, 488-505.

Dwyer, K.M. (2005). The meaning and measurement of attachment in middle and late childhood. Human Development, 48, 155-182.

Dykas, M. J. \& Cassidy, J. (2011). Attachment and the Processing of Social Information Across the Life Span: Theory and Evidence. Psychological Bulletin, 137, 19-46.

Edelstein, R. S. (2006). Attachment and emotional memory: Investigating the source and extent of avoidant memory impairments. Emotion, 6, 340-345.

Fivush, R. (1994). Constructing narrative, emotion and self in parent-child conversations about the past. In U. Neisser \& R. Fivush (Eds.), The remembering self: Accuracy and construction in the life narrative (pp. 136-157). NY: Cambridge University Press.

Fivush, R. (2006). Scripting attachment: Generalized event representations and internal working models. Attachment and Human Development, 8, 283-298.

Fivush, R., Haden, C. A. \& Reese, E. (2006). Elaborating on elaborations: The role of maternal reminiscing style in cognitive and socioemotional development. Child Development, 77, 15681588.

Griffith, J. W., Sumner, J. A., Debeer, E., Raes, F., Hermans, D., Mineka, S., Zinbarg, R. E., \& Craske, M. (2009). An item response theory/confirmatory factor analysis of the autobiographical memory test. Memory, 17, 609-623.

Gullone, E., \& Robinson, K. (2005). The Inventory of Parent and Peer Attachment - Revised (IPPA-R) for children: A psychometric evaluation investigation. Clinical Psychology and Psychotherapy, 12, 67-79.

Harley, K. \& Reese, E. (1999). Origins of autobiographical memory. Developmental Psychology, 35, $1338-1348$. 
Hudson, J. (1993). Reminiscing with mothers and others: Autobiographical memory in young twoyear-olds. Journal of Narrative and Life History, 3, 1-32.

Kerns, K.A. (2008). Attachment in middle childhood. In J. Cassidy \& P. Shaver (Eds), Handbook of Attachment (2nd edition) (pp. 366 - 382). N.Y.: Guilford.

Kovacs, M. (1992). Children's Depression Inventory. New York: Multi-Health Systems.

Kraemer, H. C., Stice, E., Kazdin, A., Offord, D., \& Kupfer, D. (2001). How do risk factors work together? Mediators, moderators, and independent, overlapping, and proxy risk factors. American Journal of Psychiatry, 158, 848-856.

Kuyken, W., Howell, R., \& Dalgleish, T. (2006). Overgeneral autobiographical memory in depressed adolescents with, versus without, a reported history of trauma. Journal of Abnormal Psychology, 115, 387-396.

Laible, D., \& Song, J. (2006). Constructing emotional and relational understanding: The role of affect and mother-child discourse. Merrill-Palmer Quarterly, 52, 44-69.

Mackinger, H. F., Pachinger, M. M., Leibetseder, M. M., \& Fartacek, R. R. (2000). Autobiographical memories in women remitted from major depression. Journal of Abnormal Psychology, 109, $331-334$.

Main, M. (1990). Cross-Cultural Studies of Attachment Organization - Recent Studies, Changing Methodologies, and the Concept of Conditional Strategies. Human Development, 33, 48-61.

Mayseless, O. (2005). Ontogeny of attachment in middle childhood. In K. A. Kerns, \& R. A. Richardson (Eds.). Attachment in Middle Childhood (pp. 1-23). New York: Guilford Press.

McKinnon, D. P., Lockwood, C. M., \& Williams, J. (2004). Trust limits for the indirect effect: Distribution of the product and resampling methods. Multivariate Behavioral Research, 39, $99-128$.

Mezulis, A.M., Hyde, J.S., \& Abramson, L.Y. (2006). The developmental origins of cognitive vulnerability to depression: Temperament, parenting, and negative life events in childhood as contributors to negative cognitive style. Developmental Psychology, 42, 1012-1025. 
Newcombe, R., \& Reese, E. (2004). Evaluations and orientations in mother - child narratives as a function of attachment security: A longitudinal investigation. International Journal of Behavioral Development, 28, $230-245$.

Preacher, K. J., \& Hayes, A. F. (2004). SPSS and SAS macros for bootstrapping indirect effects in multiple mediator models. Retrieved August 17, 2006, from http://www.comm.ohiostate.edu/ahayes/SPSS\%20programs/indirect.htm.

Preacher, K. J., \& Hayes, A. F. (2008). Asymptotic and resampling strategies for assessing and comparing indirect effects in multiple mediator models. Behavior Research Methods, 40, 879891.

Raes, F., Hermans, D., Williams, J. M. G., \& Eelen, P. (2006). Reduced autobiographical memory specificity and affect regulation. Cognition \& Emotion, 20, 402-429.

Raes, F., Hermans, D., de Decker, A., Eelen, P., \& Williams, J. M. G. (2003). Autobiographical memory specificity and affect regulation: An experimental approach. Emotion, 3, 201-206.

Raes, F., Hermans, D., Williams, J. M. G., Beyers, W., Brunfaut, E., \& Eelen, P. (2006). Reduced autobiographical memory specificity and rumination in predicting the course of depression. Journal of Abnormal Psychology, 115, 699-704.

Raes, F., Verstraeten, K., Bijttebier, P., Vasey, M. W., \& Dalgleish, T. (2010). Inhibitory control mediates the relationship between depressed mood and overgeneral memory recall in children. Journal of Clinical Child and Adolescent Psychology, 39, 276-281.

Raes, F., Williams, J. M. G., \& Hermans, D. (2009). Reducing cognitive vulnerability to depression: A preliminary investigation of Memory Specificity Training (MEST) in inpatients with depressive symptomatology. Journal of Behavior Therapy and Experimental Psychiatry, 40, 24-38.

Reese, E. \& Newcombe, R. (2007). Training mothers in elaborative reminiscing enhances children's autobiographical memory and narrative. Child Development, 78, 1153-1170.

Reese, E., Jack, F., \& White, N. (2010). Origins of adolescents' autobiographical memories. Cognitive Development, 25, 352-367. 
Ridenour, T. A., Greenberg, M. T., \& Cook, E. T. (2006). Structure and validity of people in my life: A self-report measure of attachment in late childhood. Journal of Youth and Adolescence, 35, 1037-1053.

Sarracino, D., Presaghi, F., Degni, S., \& Innamorati, M. (2011). Sex-specific relationships among attachment security, social values, and sensation seeking in early adolescence: Implications for adolescents' externalizing problem behavior. Journal of adolescence, 34, 541-554.

Shipman, K. L. \& Zeman, J. (1999). Emotional understanding: A comparison of physically maltreating and nonmaltreating mother-child dyads. Journal of Clinical Child Psychology, 28, 407-417.

Steele, M., Steele, H., Croft, C., \& Fonagy, P. (1999). Infant mother attachment at one year predicts children's understanding of mixed emotions at 6 years. Social Development, $8,161-$ 178.Target, M., Fonagy, P., \& Shmueli-Goetz, Y. (2003). Attachment representations in school-age children: The development of the child attachment interview (CAI). Journal of Child Psychotherapy, 29, 171-186.

Timbremont, B., \& Braet, C. (2002). Children's Depression Inventory: Nederlandstalige versie [Children's Depression Inventory: Dutch version]. Lisse: Swets \& Zeitlinger.

Timbremont, B. \& Braet, C. (2004). Cognitive vulnerability in remitted depressed children. Behavior Research and Therapy, 42, 423-437.

Timbremont, B., Braet, C., \& Dreessen, L. (2004). Assessing depression in youth: relation between the children's depression inventory and a structured interview. Journal of Clinical Child and Adolescent Psychology, 33, 149-157.

Valentino, K. (2011). A developmental psychopathology model of overgeneral autobiographical memory. Developmental Review, 31, 32-54.

van Vreeswijk, M. F. \& de Wilde, E. J. (2004). Autobiographical memory specificity, psychopathology, depressed mood and the use of the Autobiographical Memory Test: a metaanalysis. Behaviour Research and Therapy, 42, 731-743. 
Vrielynck, N., Deplus, S., Philippot, P. (2007). Overgeneral autobiographical memory and depressive disorder in children. Journal of Clinical Child and Adolescent Psychology, 36, 95-105.

Wang, Q. (2008). Emotion knowledge and autobiographical memory across the preschool years: A cross-cultural longitudinal investigation. Cognition, 108, 117-135.

Waters, H. S., \& Waters, E. (2006). The attachment working models concept: Among other things, we build script-like representations of secure base experiences. Attachment and Human Development, 8, 185-197.

Waters, H.S., Scandariato, I., Waters, T., Bianchini, A., Horan, E., \& Bosmans, G. (2011). Middle Childhood Attachment Narratives: Organized Around a Secure Base Script? Poster presentation on Society of Research in Child Development Biennial meeting, Montreal (Canada).

Weisz, J. R., McCarthy, C. A., \& Valeri, S. M. (2006). Effects of psychotherapy for depression in children and adolescents: A meta-analysis. Psychological Bulletin, 132, 132-149.

Williams, J. M. G. (1996). Depression and the specificity of autobiographical memory. In D. C. Rubin (Ed.), Remembering our past: Studies in autobiographical memory (pp. 244-267). Cambridge, England: Cambridge University Press.

Williams, J. M. G., \& Broadbent, K. (1986). Autobiographical memory in suicide attempters. Journal of Abnormal Psychology, 95, 144-149.

Williams, J. M. G., Barnhofer, T., Crane, C., Hermans, D., Raes, F., \& Watkins, E., et al. (2007). Autobiographical memory specificity and emotional disorder. Psychological Bulletin, 133, $122-148$

\section{Footnotes}

\footnotetext{
${ }^{1}$ The analyses were also repeated with an AMT-Specificity proportion score calculating by dividing the number of specific memories by the total number of memories (overgeneral and specific memories taken together). The same results were found. If requested, the authors can provide all details.
} 


\section{Acknowledgement}

We would like to thank Veerle Decaluwe and Min Sleebus of the Lessius University College in Antwerp for their cooperation.

Table 1: Correlations between the Study's main variables

$\begin{array}{llll}\text { AMT-Specificity } & \text { Trust } & \text { Communication } & \text { Depression }\end{array}$

\begin{tabular}{lllll}
\hline AMT-Specificity & 1 & & & \\
Trust & -.08 & 1 & & \\
Communication & $.25^{*}$ & $.54^{* * *}$ & 1 & 1 \\
Depression & $-.22^{*}$ & -.15 & -.15 & 9.96 \\
\multicolumn{1}{c}{$M$} & 6.5 & 35.54 & 15.49 & 8.23 \\
\hline$S D$ & 2.15 & 3.71 & 2.65 & \\
\hline
\end{tabular}

$* p<.05 ; * * * p<.001$ 
Table 2: Multiple Regression Analysis with Communication as Predictor of AMT-Specificity and Depression, Age, and Gender as Control Variables

\begin{tabular}{|c|c|c|c|c|c|}
\hline & $R^{2}$ & $F$ & $D f$ & $f^{2}$ & $\beta$ \\
\hline Step 1 & .05 & 1.82 & 2,77 & .05 & \\
\hline Age & & & & & -.04 \\
\hline Gender & & & & & $-.22^{\dagger}$ \\
\hline Step 2 & .08 & 3.19 & 1,76 & .09 & \\
\hline Depression & & & & & -.15 \\
\hline Step 3 & .15 & 5.65 & 1,75 & .18 & \\
\hline Communication & & & & & $.26^{*}$ \\
\hline
\end{tabular}


${ }^{\dagger} p<.1{ }^{*} p<.05$; Gender was dummy coded(Boys $=1$; Girls $=2$ ); $f^{2}=$ Cohen's $f^{2}$ effect size, reflecting small $(>.02)$ to medium (>.15) effects; $\beta$ s are reported for the last step of analysis.

Figure 1: The indirect effect of Trust on Autobiographical Memory Specificity through Communication

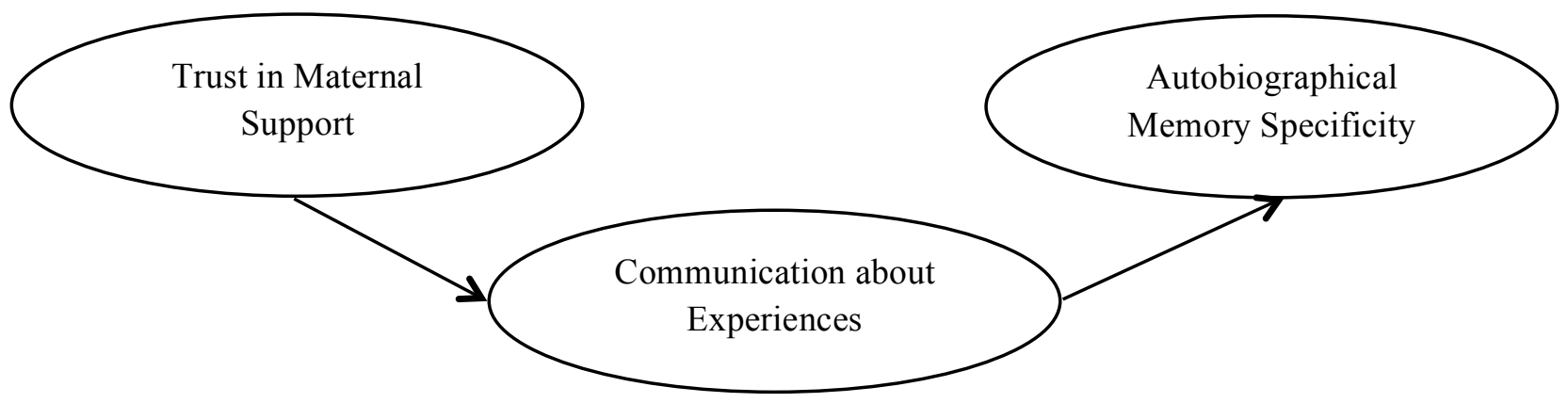

